\title{
The Value of Inter Ictal EEG in the Diagnosis of Epilepsy at the Clinical Neurophysiology Laboratory of FANN Teaching Hospital of Dakar
}

\author{
Michel-Arnaud Saphou Damon ${ }^{1,}$, , Franck-Ladys Banzouzi ${ }^{1}$, Anna Modji Basse ${ }^{1}$, \\ Hilaire Ewodo Touna ${ }^{1}$, Marième-Soda Diop-Sene ${ }^{1}$, Fidélie Scholastique Ngoungoure Halima ${ }^{1}$, \\ Prisca-Rolande Bassole ${ }^{2}$, Adjaratou Dieynabou Sow ${ }^{1}$, Lala Bouna Seck ${ }^{1}$ \\ ${ }^{1}$ Neurological Clinic Ibrahima P. Ndiaye, Fann Hospital University - Cheikh Anta Diop University of Dakar (UCAD), Dakar, Senegal \\ ${ }^{2}$ Department of Neurology, El Hadj Ibrahima Niasse Private University-College of Medicine Saint Christopher Ibar Mar DIOP, Dakar, \\ Senegal
}

Email address:

map.saphoudamon@gmail.com (Michel-Arnaud S. D.)

${ }^{*}$ Corresponding author

\section{To cite this article:}

Michel-Arnaud Saphou Damon, Franck-Ladys Banzouzi, Anna Modji Basse, Hilaire Ewodo Touna, Marième-Soda Diop-Sene, Fidélie Scholastique Ngoungoure Halima, Prisca-Rolande Bassole, Adjaratou Dieynabou Sow, Lala Bouna Seck. The Value of Inter Ictal EEG in the Diagnosis of Epilepsy at the Clinical Neurophysiology Laboratory of FANN Teaching Hospital of Dakar. Clinical Neurology and Neuroscience. Vol. 4, No. 4, 2020, pp. 82-85. doi: 10.11648/j.cnn.20200404.13

Received: November 2, 2020; Accepted: November 17, 2020; Published: November 27, 2020

\begin{abstract}
Introduction: The diagnosis of epilepsy is mainly based on clinical features. Electroencephalography (EEG) is mainly essential on classifying epilepsy and epileptic syndromes. Our purpose is to demonstrate EEG has a role in setting the diagnosis of epilepsy. Method: We have studied the EEG of 775 patients of all age-groups registered in the EEGs laboratory of Fann Teaching hospital from July $1^{\text {st }}$ to November $15^{\text {th }} 2018$. We included all patients not previously known with epilepsy. The EEGs conclusion were taken from the digital database. We have split them into two groups EEG abnormal versus EEG normal. The statistical analyzes were made by Epi Info 7.2.3.1. Results: The median age was 14 years old. The patient age range was from 38 days to 86 years. Patients with abnormal EEG were at $38 \%$ of the total. After univariate study were significantly associated with an abnormal EEG patients who came for focal onset crisis (74\%) and those who came for spasm (84\%). All with status epilepticus had abnormal EEG. Patients with generalized crises had an abnormal EEG in $60 \%$ but that was not significant. Diagnosis seek by pediatrician was significantly associated abnormal EEG. Conclusion: EEG is a very affordable test which plays a key role on the diagnosis of epilepsy. It sensitivity is closely linked with the experience of the ordering physician. Broad awareness of epilepsy among healthcare professionals and the community would be an important step in improving patient's management.
\end{abstract}

Keywords: Diagnosis, Epilepsy, Inter Ictal EEG, Pediatric Neurology

\section{Introduction}

The EEG is a critical tool in the diagnosis and management of epilepsy. Since its discovery in 1929 by Hans Berger [1] It has undergone many improvements and mutations since the very first device used by Berger and developed by Siemens [2,3]. Despite all the advances in neuroimaging, the EEG still has a prominent place in the diagnosis and therefore the management of epilepsy [4]. The diagnosis of epilepsy is clinic. However, the EEG remains crucial to confirm and classify epilepsy, to define it as a syndrome, to assess the response to antiepileptic drugs (AED) [4-7]. Some authors have evaluated the role that the EEG could play in the diagnosis of epilepsy on relatively homogeneous series: pediatrics; sleep recordings; intensive care patients $[4,6,8-10]$.

Our study, which involved a heterogeneous population including hospitalized and non-hospitalized patients, aims to determine the contribution of the interictal sleep and/or 
wakefulness EEG with or without video to the diagnosis of epilepsy.

\section{Materials and Method}

We conducted a monocentric, cross-sectional, retrospective study in the clinical neurophysiology laboratory of the Ibrahima Pierre Ndiaye Neurology Clinic of the CHN Fann in Dakar. The EEG unit of the laboratory includes three (03) examination rooms for the realization of standard wakefulness EEG and nap sleep EEG coupled with EEG video. Continuous or Holter-EEG recordings are performed on patients hospitalized in the neurology department. We retrospectively recorded the EEG results of patients, not followed for epilepsy, of any age received from July 1 to November 15, 2018 for investigation of a symptomatology suggestive of epilepsy. Patients for whom the EEG was performed as part of epilepsy follow-up or therapeutic adjustment were not included. Our patients were grouped into 7 age groups arbitrarily distributed as follows: (1) newborns from 0 to 28 days old; (2) infants from 29 days old to less than 03 months old; (3) children from 03 months old to less than 05 years old; (4) older children from 05 years old to less than 10 years old; (5) adolescents from 10 years old to less than 18 years old; (6) young adults from 18 years old to less than 30 years old; and (7) adults represented by all subjects over 30 years old received at the EEG and meeting our inclusion criteria. This arbitrary distribution more or less mirrored the age distribution of epileptic syndromes. The EEG recording is digitized from the Micromed ${ }^{\circledR}$ and Neurosoft ${ }^{\circledR}$ systems. Cortical electrical activity is collected from electrodes mounted on helmets according to the international 10-20 system recommended by the International Federation of EEG and Clinical Neurophysiology Societies. Intermittent light stimulation (SLI) was applied to all patients older than 3 months and hyperpnea (HPN) to all patients older than 3 years in the absence of contraindications. The sleep obtained was a siesta sleep. Sleep was obtained either spontaneously or, most often, after sleep deprivation. The use of sleep inducers (Alimémazine syrup: Théralène ${ }^{\circledR}$ ) was sometimes necessary especially in infants and children. The duration of wakefulness recording is 20 minutes minimum and 1 hour minimum for sleep recording. The different stages of sleep were exclusively characterized by the presence of physiological sleep patterns. The simultaneous recording of the video allowed precise electroclinical diagnoses. All the recorded EEGs are then directed and saved on a local server from where they are interpreted by experienced neurologistneurophysiologists. The sensitivity of the results rendered is improved by collegial reading of the most difficult tracings. The interpretation reports are saved on the server and printed in two copies. One copy signed by the neurologistneurophysiologist and given to the patient and the other copy kept in the physical archives of the laboratory. The conclusion of the EEG report was our main judging criterion. We dichotomized it into normal and abnormal EEG. The EEG was considered abnormal when the neurophysiologist's interpretation revealed paroxysmal graphoelements with focal or generalized onset, puffy, discharge, rhythmic, pseudorhythmic, periodic or pseudoperiodic spike or spikewave or poly-spike-wave or slow-wave or background rhythm abnormalities. To better appreciate the significance of our results, we also studied the demographics of our population, the most frequently encountered indications which we classified into indication groups, the type of registration performed and the specialty of the prescriber. The prescribers were divided into (01) Neurologist, (02) Pediatrician, (03) Psychiatrist, (04) General practitioner and (05) Other prescribers. All other physicians were included in the "general practitioner" group, and all non-physician prescribers were included in the "other prescribers" group. No distinction was made between residents, interns and specialists within the same specialty. A univariate analysis allowed us to refine our results by cross-referencing the various secondary judging criteria to the primary judging criterion.

The EEG results used came from the digital and physical databases of the laboratory. Our data were analyzed by the software Epi info version 3.5.3. The figures were produced using Microsoft office Excel Office 2016. Descriptive statistics were applied to condense and order the variables. The qualitative variables were expressed by their graphical representations through various graphs. Statistical significance was established at the $5 \%$ level $(\mathrm{p}<0.05)$. the data privacy was guaranteed and all the data were anonymized.

\section{Results}

We retained 775 patients. The median age was 14 years. The minimum age was 38 days and the maximum age was 86 years. The age distribution was homogeneous, we did not have any newborns. Of the 775 EEGs performed, 296 had an abnormal EEG (38.19\%) and $61.81 \%$ had a normal EEG. The main indications of the EEG were convulsive seizures (29.07\%), generalized tonic-clonic seizures (CGTC) (23.51\%), psychomotor retardation (RPM) (6.98\%) and headache $(6.20 \%)$ (Table 1$)$.

Table 1. Main indications of EEG.

\begin{tabular}{lll}
\hline Indications & Fréquence & Percent \\
\hline Absence & 25 & $3.23 \%$ \\
Other indications & 136 & $17.57 \%$ \\
Headaches & 48 & $6,20 \%$ \\
GTC seizures & 182 & $23.51 \%$ \\
Convulsive crises & 225 & $29.07 \%$ \\
Partial crises & 64 & $8,26 \%$ \\
Status epilepticus & 4 & $0.52 \%$ \\
Psychomotor retardation & 54 & $6.98 \%$ \\
Spasms & 13 & $1.68 \%$ \\
Cognitive disorders & 23 & $2.97 \%$ \\
Total & 774 & $100.00 \%$ \\
\hline
\end{tabular}

Sleep recordings (sleep EEG and sleep-wake EEG) provided more abnormal EEGs and accounted for $73.31 \%$ or $\mathrm{n}=217$ abnormal EEGs and $28.59 \%$ of all our patients (Figure 
1).

All EEGs requested for status epilepticus came abnormal. After univariate analysis the EEGs requested other variables were also significantly associated with an abnormal EEG: Children's age group $(50.78 \%, \mathrm{p}=0.001)$; hold children's age group $(61.46 \%, \mathrm{P}<0,0001)$; when requested for spasms $(84.62 \%, p=0,0076)$; when requested for focal-motor seizure $(74 \%, p=0.002)$ and when requested by the pediatrician $(51.35 \%, \mathrm{p}=0.01)$ (Table 2).

Table 2. Variables associated with an abnormal EEG.

\begin{tabular}{llll}
\hline Variables & Normal EEG & Abnormal EEG & P value \\
\hline Partial motor seizures & $13(26 \%)$ & $37(74 \%)$ & $<0.0001$ \\
Spasms & $2(15.38 \%)$ & $11(84.62 \%)$ & $<0.0001$ \\
S. E & - & $4(100 \%)$ & - \\
Children & $63(49.22 \%)$ & $65(50.78 \%)$ & 0.001 \\
Older children & $37(38.54 \%)$ & $59(61.46 \%)$ & $<0.0001$ \\
Pediatrician & $54(48.65 \%)$ & $57(51.35 \%)$ & 0.01 \\
\hline
\end{tabular}

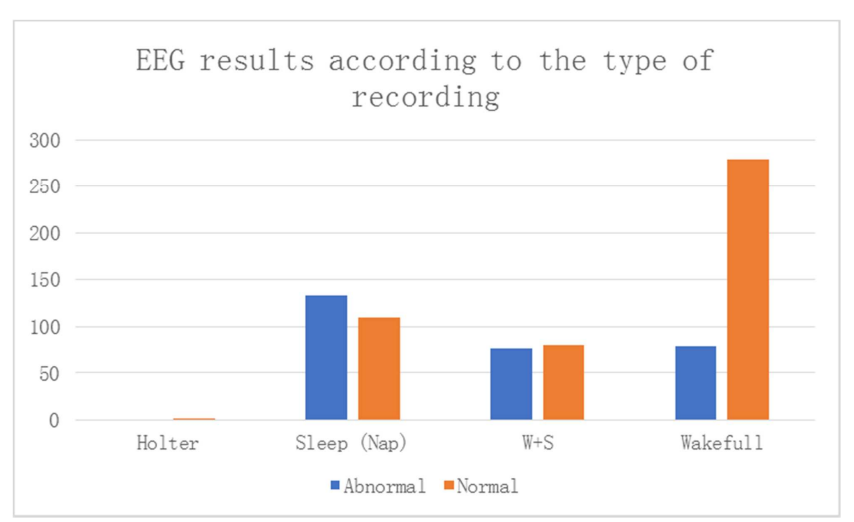

Figure 1. EEGs results according to the type of recording method.

Indication of generalized tonic-clonic seizure 115 (63.19\%) was associated with a nonsignificant abnormality. In another hand, were significantly normal EEGs in young adult's age group $117(72.22 \%, \mathrm{p}=0.0013)$; EEGs in adult's age group 108 (74.48, $\mathrm{p}=0,0003)$; EEG requested by the neurologist $154(52.92 \%, \mathrm{p}<0,0001)$ and EEG requested by the general practitioner $127(77.44 \%, \mathrm{p}<0,0001)$.

\section{Discussion}

At the end of our study, $38 \%$ of the EEGs performed as part of the diagnosis of epilepsy were abnormal. For 4 out of 10 patients, the EEG thus contributed to the diagnosis of epilepsy. These results support the use of the EEG as a diagnostic tool for epilepsy. Our results are comparable to those of Cees A. Van Donselaar (1992) who affirmed the major role of the EEG in a patient with an inaugural crisis [11]. In their review of the role of the EEG in epilepsy Soheyl Noachtar, Jan Rémi (2009) also stated that the EEG plays a key role in the diagnosis of epilepsy [4]. Our results are those of EEGs performed on patients who all had clinical manifestations justifying the performance of an EEG. They are different from those of Gregory et al (1993) who showed that only $0.5 \%$ of 13658 healthy subjects from the U.S. Army had EEG abnormalities, and after a follow-up of 7 to 30 years, only 1 of these $0.5 \%$ had epilepsy [12]. This difference between our two studies is certainly related to the inclusion criteria of patients that were not the same. This reinforces our hypothesis that the EEG contributes to the diagnosis of epilepsy.

All of the EEGs requested for SE were abnormal as well as $85 \%$ of the EEGs requested for spasms and $74 \%$ of the EEGs requested for partial motor seizures with, for all these cases, an indication to start treatment. Fontaine (2006), Van Donselaar (1992) and Noachtar (2006) also demonstrated that the EEG was reliable for deciding whether to initiate antiepileptic treatment in the event of an inaugural seizure [4, $11,13]$. In all three indications, diagnosis is relatively easy at the clinic and the patient is often seen by a neurologist or pediatrician. The knowledge of seizure symptomatology by the EEG prescriber is therefore important to improve the sensitivity of the EEG.

The 3-month to 9-year age groups were more often associated with an abnormal EEG. The role of the EEG in confirming the diagnosis of epilepsy is therefore higher in children than in adolescents and adults. This may be explained by the higher frequency of epilepsy and epileptic syndromes in these age groups [14-16].

The likelihood of having an abnormal EEG was high when the prescriber was a pediatrician. However, there was no significant relationship between an abnormal EEG and other prescribers. Our results are similar to those of Tekin Orgun (2018), which showed that an increase in the number of pediatric neurologists contributed to improved EEG sensitivity [17]. This can be explained by the fact that the majority of our patients were seen by pediatricians but especially by the fact that epilepsy is very frequent in pediatrics. Pediatricians therefore have a daily experience of seizures which refines their EEG requests.

In our study the sleep EEG resulted in a higher number of abnormal EEGs. In a study of sleep EEGs, Assi (2000) suggested that recording night sleep had a greater diagnostic gain than recording nap sleep and wakefulness EEGs [6]. Sleep recording is therefore more sensitive than wakefulness recording in the diagnosis of epilepsy.

However, there are limitations to our study: although our results are consistent with the literature in stating that the EEG contributes to the diagnosis of epilepsy after a first seizure, patients in our study were not followed up and the proportion of epilepsy confirmed by the EEG could not be accurately determined. On the other hand, the advantage of 
our methodology is the fact of having access to a very large number of patients without prejudging their origin, which reduces the selection bias linked to the training of the prescriber. The results thus obtained are therefore closer to the reality of EEG practice at the Neurology Clinic of the Fann National Hospital Center.

\section{Conclusion}

The EEG is an inexpensive and non-invasive examination that is regularly prescribed in neurophysiology. The interictal EEG has an important role in the diagnosis of epilepsy. Its sensitivity is all the higher the more precise the indication is, the more the prescriber has training in neurological pathology (neurologist, pediatrician, neuropediatrician). The higher distribution of abnormalities in pediatrics makes it necessary to sensitize emergency room physicians, general practitioners, school physicians and family physicians to the manifestations of epilepsy. However, knowledge of EEG sensitization maneuvers requires well-trained electrophysiology technical staff. Despite technological advances, particularly in brain imaging, the EEG remains indispensable for the diagnosis of epilepsy. The presence of EEG abnormalities is strongly suggestive of epilepsy, but the absence of abnormalities does not necessarily imply the absence of epilepsy, just as isolated EEG abnormalities do not necessarily imply the existence of epilepsy. Association with the clinic remains the rule.

\section{Conflict of Interest}

All the authors have no conflict of interest.

\section{Acknowledgements}

I would like to thank my wife and our three children for their constant support and the strength they give me daily. I would also like to thank the entire department of clinical neurophysiology of Fann for the unaffordable opportunity given to me to learn EEG.

\section{References}

[1] Gloor P. Hans Berger and the discovery of the electroencephalogram. Electroencephalogr Clin Neurophysiol. 1969; Suppl 28: 1-36.

[2] Herrmann CS, Strüber D, Helfrich RF, Engel AK. EEG oscillations: From correlation to causality. International Journal of Psychophysiology. 2016; 103: 12-21.

[3] Mecarelli O. Past, Present and Future of the EEG. In: Clinical Electroencephalography [Internet]. 2019 [cited $2020 \mathrm{Feb} 4$ ]. p. 3-8. Available from: https://doi.org/10.1007/978-3-03004573-9.

[4] Noachtar S, Rémi J. The role of EEG in epilepsy: A critical review. Epilepsy \& Behavior. 2009; 15 (1): 22-33.
[5] Manfredonia F, Saturno E, Lawley A, Gasverde S, Cavanna $\mathrm{AE}$. The role of electroencephalography in the early diagnosis of non-convulsive status epilepticus in elderly patients with acute confusional state: Two possible strategies? Seizure. 2019; 73: $39-42$.

[6] Assi B, Tuillas M, Tapie P. Apport de l'electroencephalogramme de sommeil dans le diagnostic de l'epilepsie. Médecine d'Afrique Noire. 2000; 47 (2): 61-4.

[7] Chen H, Koubeissi MZ. Electroencephalography in Epilepsy Evaluation: CONTINUUM: Lifelong Learning in Neurology. 2019 Apr; 25 (2): 431-53.

[8] Yazbeck E, Nguyen S. L'apport de l'EEG au sein de la clinique de l'épilepsie pédiatrique. Neurophysiologie Clinique/Clinical Neurophysiology. 2017 Jun; 47 (3): 219.

[9] Nguefack S, Enyama D, Chiabi A, Sini V, Mah E, Bogne JB, et al. Anomalies de l'électro-encéphalogramme en neurologie pédiatrique: à propos de 500 enregistrements à l'Hôpital Gynéco-Obstétrique et Pédiatrique de Yaoundé (Cameroun). Pan African Medical Journal [Internet]. 2013 [cited 2020 Feb 2]; 15. Available from: http: //www.panafrican-medjournal.com/content/article/15/63/full/.

[10] Rosenow F, Klein KM, Hamer HM. Non-invasive EEG evaluation in epilepsy diagnosis. Expert Review of Neurotherapeutics. 2015; 15 (4): 425-44.

[11] van Donselaar CA, Schimsheimer R-J, Geerts AT, Declerck AC. Value of the Electroencephalogram in Adult Patients With Untreated Idiopathic First Seizures. Archives of Neurology. 1992; 49 (3): 231-7.

[12] Gregory RP, Oates T, Merry RTG. Electroencephalogram epileptiform abnormalities in candidates for aircrew training. Electroencephalography and Clinical Neurophysiology. 1993; 86 (1): 75-7.

[13] Fountain NB, Freeman JM. EEG Is an Essential Clinical Tool: Pro and Con. Epilepsia. 2006; 47 (s1): 23-5.

[14] Ochoa-Gómez L, López-Pisón J, Lapresta Moros C, Fuertes Rodrigo C, Fernando Martínez R, Samper-Villagrasa P, et al. Estudio de las epilepsias según la edad de inicio, controladas durante 3 años en una unidad de neuropediatría de referencia regional. Anales de Pediatría. 2017; 86 (1): 11-9.

[15] Thijs RD, Surges R, O'Brien TJ, Sander JW. Epilepsy in adults. The Lancet. 2019 Feb; 393 (10172): 689-701.

[16] Vignoli A, Canevini MP. Genetic Generalized Epilepsies. In: Mecarelli O, editor. Clinical Electroencephalography [Internet]. Cham: Springer International Publishing; 2019 [cited 2020 Mar 28]. p. 461-73. Available from: http://link.springer.com/10.1007/978-3-030-04573-9_27.

[17] Tekin Orgun L, Arhan E, Aydin K, Rzayeva T, Hirfanoglu T, Serdaroglu A. What has changed in the utility of pediatric EEG over the last decade? TURKISH JOURNAL OF MEDICAL SCIENCES [Internet]. 2018 [cited 2020 Mar 27]; 48 (4). Available from: http://online.journals.tubitak.gov.tr/openDoiPdf.htm?mKodu= sag-1712-188. 